\title{
The Effects on Cells Mobility Due to Exposure to EMF Radiation
}

\author{
Ashraf A. Aly ${ }^{1}$, Safaai Bin Deris ${ }^{2}$, and Nazar Zaki ${ }^{3}$ \\ ${ }^{1,2}$ Faculty of Computer Science and Information Systems, Universiti Teknologi Malaysia \\ ${ }^{3}$ College of Information Technology, UAE University, UAE \\ ashraf.ahmed@uaeu.ac.ae, safaaidutm.my, nzakiduaeu.ac.ae
}

\begin{abstract}
Although the important role of the immune system in defending the human body against infections and cancer, only few studies on the possible effects of radiofrequency radiation on the function of human immune cells have been undertaken. The present study was performed to investigate whether radio frequency $(R F)$ field exposure could affect the activity of human immune system cells by studying the activity and behavior of human leukocytes (white blood cells) upon exposure to radiofrequency fields. Human blood Leukocytes were exposed to different temperatures and $1800 \mathrm{MHz}$ RF radiation (SAR of 1.25 $W / K g$, Power density of $0.1 \mathrm{mW/cm} 2$ ) from a mobile phone when placed within a distance of $5 \mathrm{~cm}$ from the microscope stage. Our results indicated that when $1800 \mathrm{MHz}$ RF field was applied, the speed increased above the value observed at the same temperature, and the maximum speed exceeded that measured value at any temperature by approximately 50\%. The average time for the leukocytes to respond to the effect of $R F$ radiation was approximately $2.5 \mathrm{~min}$. Under the effect of $R F$ exposure, significant change observed in Leukocytes movement direction to be perpendicular to the chemotactic direction and in parallel with the mobile phone position. Also significant change in leukocytes behavior, include changing shape much faster. The cells were shrinking, expanding, and rolling.
\end{abstract}

\section{Key words}

EMF Radiation, Radio Frequency $(R F)$, Cells Mobility.

\section{INTRODUCTION}

In recent years, the public concern about the possible health hazards of radio frequency (RF) field exposure from mobile phones has increased and initiated many studies on the possible adverse consequences on human health [1][3]. The possible interaction between the radio frequency (RF) electromagnetic radiation and its biological effects on human tissues particularly on the brain, cancer, and the human immune system have been investigated. Although the important role of the immune system in defending the human body against infections and cancer, only few studies on the possible effects of radiofrequency radiation on the function of human immune cells have been undertaken [9]. The strip source diffusion technique which previously used [4] to study the chemotactic response of the Leukocytes cells by studying the ability of leukocytes to track cyclic-adenosine monophosphate (C-AMP) concentration gradient. The strip source diffusion technique attracted us to use the approach [4] as a way of studying the possible effects of radio frequency electromagnetic radiation on Leukocytes as a component of the human immune system. In the present work we have some factors which affect the motion and behavior of the leukocytes such as temperature, chemo-attractant concentration gradients, type of

DOI : 10.5121/acij.2011.2401 
leukocytes (Neutrophil, Eosinophil, Lymphocyte, and Monocyte), and the cells age (with fresh blood we get the best cells activity). On the other hand, there are other unknown variables affect the activity and the behavior of the leukocytes cells such as the condition and the characteristics of the human donors. In our work approximately $80 \%$ of the experiments showed a good chemotactic response to C-AMP. However, the mechanism of the interaction between the cellular phone systems and the effect of EMF still unclear. There is possibility that the induced electric field due to exposure to EMF radiation could cause cellular changes.

Leukocytes (WBC) playing essential role in our human immune system. It is the body defense against invading bacteria, viruses, fungi, and parasites. Leukocytes attack the invading organisms (pathogens), by identifying them, attaching, destroying them, and take them out of the blood, and continuously produce antibodies against that organism to the rest of the body life.

The aim of our work is to study the effects of mobile phones radio frequency radiation on the immune system by investigate the activity and behavior of human leukocytes (white blood cells) upon exposure to radio frequency fields in vitro by using microscopic techniques. This is done by investigating the ability of leukocytes to track cyclic-Amp concentration gradients, and changes in cells activity.

\section{RELATED WORK}

Evidence has been reported about the possible health effects such as; brain tumor, blood-brain barrier (BBB) permeability function, sleep problems, cognitive function, DNA damage, immunity system function, stress reaction, and increased incidence rate of traffic accidents due to using mobile phone during driving.

Recently, many studies have concerns about the association between exposure to EMF radiation and the risk of cancer. Some studies reported association between cancer and the use of some appliances, such as television sets, hair dryers, radio and television transmitters, TV towers, and electric razors. Other studies has concerns regarding human health effects due to exposure to EMF radiation, such as mobile phones as in Hardell et al. 1999 [10]; Muscat et al. 2000 [11]; Inskip et al. 2001 [12]; Johansen et al. 2001 [13]; and Rothman et al. 1996 [14]. Several studies have linked exposure to extremely low frequency electromagnetic fields (ELF-EMF) and increase the risk of childhood leukemia as in Ahlbom et al., 2000[15]; Deadman et al. 1999 [16]; Foliart et al. 2002 [17]; and Foliart et al. 2001[18].

\section{MATERIALS AND METHOD}

\subsection{Materials}

Cyclic-AMP (Cyclic Adenosine3', 5'-Monophos- phate) is very important cell transduction signal elements (was discovered in 1960`s), and it represents an indirect way of investigating molecular events occurring at the membrane. Cyclic-AMP as a second messenger involve with intracellular signaling, which carry signals from the cell surface to proteins within the cell. CAMP was used to create a concentration gradient of the chemo-attractant a stripe source diffusion technique [4]. C-AMP of $3.3 \mathrm{mg}$ was dissolved in $0.1 \mathrm{ml}$ of serum to obtain a known concentration of the chemo-attractant. Then a needle was used to make a stripe ( $1 \mathrm{~mm}$ wide) of the solution on the slide. The solution stripe was left to get dry. We used human blood from at least 25 adult donors to make two slides for each sample. One or two cells were used from each slide. The blood was drawn into $4.5 \mathrm{ml}$ vacationer tubes lined with $0.5 \mathrm{ml}$ of sodium citrate. Once the blood was collected, the tubes were slowly turned upside down several times to effectively mix the anticoagulant with the blood. The tubes were then centrifuged for $3 \mathrm{~min}$ at $150 \mathrm{G}$ using a centrifuge machine. Separate layers were formed of red blood cells, leukocytes (white blood 
cells) including leukocytes, platelets, and serum. The mixture of leukocytes and platelets was concentrated at the boundary between the plasma and the red blood cells. A small sample containing leukocytes, platelets, and few red cells was drawn from the boundary layer using a micropipette.

\subsection{Method}

To create a concentration gradient of the chemo-attractant a stripe source diffusion technique [4] was used. $3.3 \mathrm{mg}$ of C-AMP (Cyclic Adenosine3', 5'-Monophos- phate) was dissolved in $0.1 \mathrm{ml}$ of serum to obtain a known concentration of the chemo-attractant. Then a needle was used to make a stripe ( $1 \mathrm{~mm}$ wide) of the solution on the slide. Once the solution stripe was completely dry, a micropipette was used to extract a small sample of leukocytes and they were placed about $0.5 \mathrm{~cm}$ from the left side of the microscope slide. The drop of fluid containing leukocytes was covered with a cover slip to create a layer of about $15 \mu \mathrm{m}$ thick. Then the cover slip was slid to the point such that C-AMP strip was covered along the cover slip's one side. The chemoattractant diffused and created a concentration and concentration gradient that were numerically calculated as functions of time and position by using the equations developed in [4] and [5]. The cover slip was sealed with Vaseline around the edges to reduce the effects of pressure, temperature, and vibration on the movement of the leukocyte cells and to prevent the sample from drying out. The slide was then placed on the microscope stage that had been heated to the desired temperature.

The heater had no measurable effect on the RF field pattern and the $60-\mathrm{Hz}$ fields were much less than $1 \mathrm{~T}$. The leukocytes cells were exposed to $1800 \mathrm{MHz}$ radio frequency radiation (SAR of 1.25 $\mathrm{W} / \mathrm{Kg}$, Power density of $0.1 \mathrm{~mW} / \mathrm{cm}^{2}$ ) from mobile phone placed within a distance of $5 \mathrm{~cm}$ from the microscope stage. The temperature rise resulting from the RF power was measured to be less than the $0.1^{\circ} \mathrm{C}$ resolution of our measuring equipment.

The slide was placed on the heated stage for about $15 \mathrm{~min}$, thus allowing it to reach steady state. A leukocyte was identified by finding a cell that was 1.5 to 2.5 times the size of a red blood cell, changing shape, and moving. After a leukocyte was found meeting the above requirements, its movements were tracked on the computer monitor with the help of a tracking system as function of time and position. Control data were determined by running a series of experiments, at a constant strip concentration of C-AMP and incrementing the temperature by one degree from 29 ${ }^{\circ} \mathrm{C}$ to $43{ }^{\circ} \mathrm{C}$.

\section{RESULTS AND DISCUSSION}

Our experiments were based on the observation of the motion of a life leukocyte cells, we kept the concentration of C-AMP constant, and the temperature of the microscope slide had been heated to the desired temperature (from $29^{\circ} \mathrm{C}$ to $43^{\circ} \mathrm{C}$ ), and then observe the motion and the behavior of 30 active leukocytes (approximately $80 \%$ of the cells showed a well response to CAMP) cells both with and without the application of the RF. For the exposed cells, the motion of the cells was observed for about 15 min before applying the RF radiation and for about 15 min after application of RF radiation.

A typical tracking of leukocytes on the calibrated screen is shown in Fig. 1, and Fig. 2. Significant changes in leukocytes movement direction also occur. The movement direction is observed to be perpendicular to the direction along the C-AMP gradient and random movements are suppressed and without RF these cells moved toward the C-AMP stripe, and these results indicate that RF radiation eliminate or reduce the effect of C-Amp on the leukocytes mobility. 
Our experimental results show significant change in leukocytes behavior (see table 1) upon the application of RF fields, including more rapid changes in shape, (cells shrinking, expanding, and rolling). The leukocytes tracking speed increased rapidly upon raising temperature between $29^{\circ} \mathrm{C}$ and $40^{\circ} \mathrm{C}$, peaks and decreased after $40^{\circ} \mathrm{C}$. Under the exposure to $\mathrm{RF}$ radiation, the leukocytes movement speed will rise by about $50 \%$ above the speeds at the same temperatures without the RF. See Fig. 3.

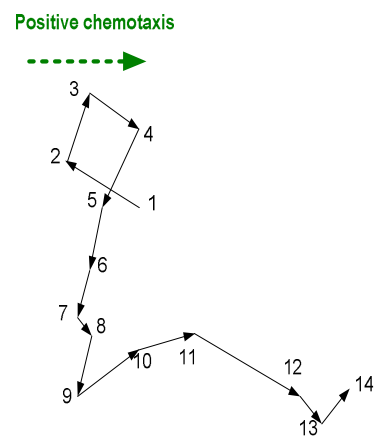

Figure 1. Leukocytes cell movement without RF radiation exposure.

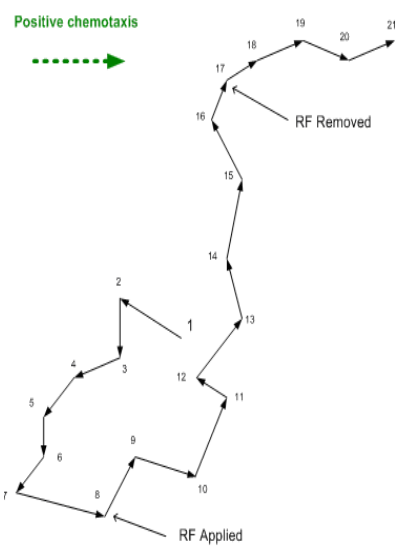

Figure 2. Leukocytes cell movement under RF radiation exposure.

Table 1. Cells behavior results.

\begin{tabular}{|l|c|c|}
\hline \multicolumn{1}{|c|}{ Cell behavior } & Without RF radiation & With RF radiation \\
\hline $\begin{array}{l}\text { Cell response time } \\
\text { constant to RF } \\
\text { radiation }\end{array}$ & The cells act normally & 2.5 minutes \\
\hline Av. Movement speed & $3.45 \mu \mathrm{m} / \mathrm{min}$ & $6.40 \mu \mathrm{m} / \mathrm{min}$ \\
\hline Changing shape & Normal & Faster \\
\hline Movement direction & Sideward direction & Upward direction \\
\hline
\end{tabular}




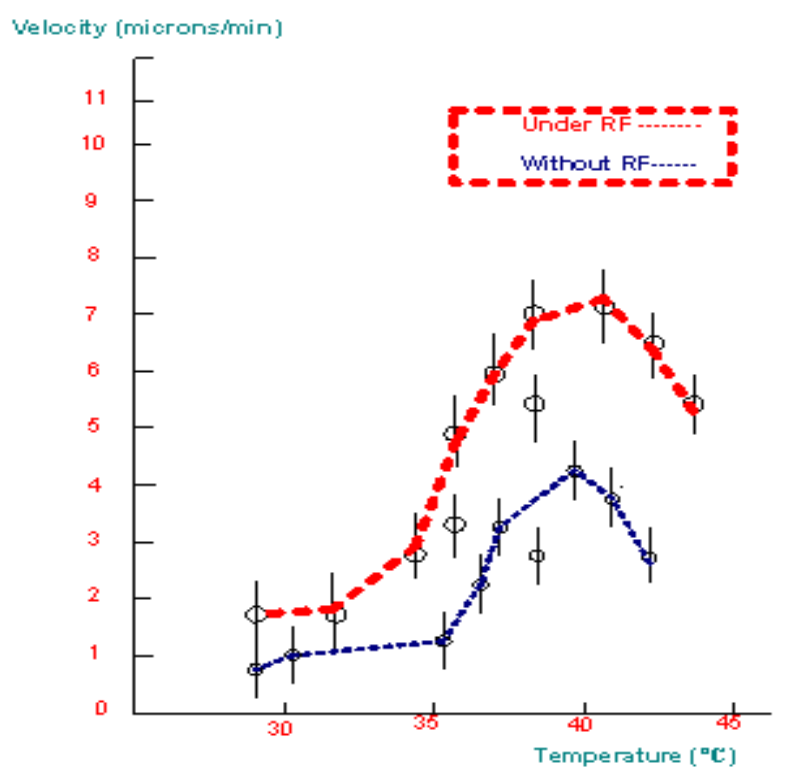

Figure 3. Leukocytes velocity as a function of temperature.

The velocity for the cells without RF exposure was $(\mathrm{v})=3.45 \pm 1.12 \mu / \mathrm{min}$ (mean and standard deviation) but with the exposure, the average velocity was (v) $=6.40 \pm 0.90 \mu / \mathrm{min}$.The average time for the leukocytes to respond to the effects of RF was about $2.7 \mathrm{~min}$. One of the significant results we found, RF radiation caused damage to the leukocytes cells from specific person's blood (three samples shows the same result) as shown in Fig. 4, the cells expanded and lost its ability to move.

It is to be noted that leukocytes are the only cells are moving both with and without the application of the RF. However, no effects from RF were observed on the platelets or red blood cells. Our observation shows leukocytes from fresh blood were more active than second day blood. In our work we were able to control some factors that affect the mobility and the activity of leukocytes such as the concentration gradients and temperature, we are expecting other factors to be involve and affecting the mobility and the activity of leukocytes such as the type of leukocytes, its age, the amount of anticoagulant used, and the health condition (such as infection and stress) of the donors.

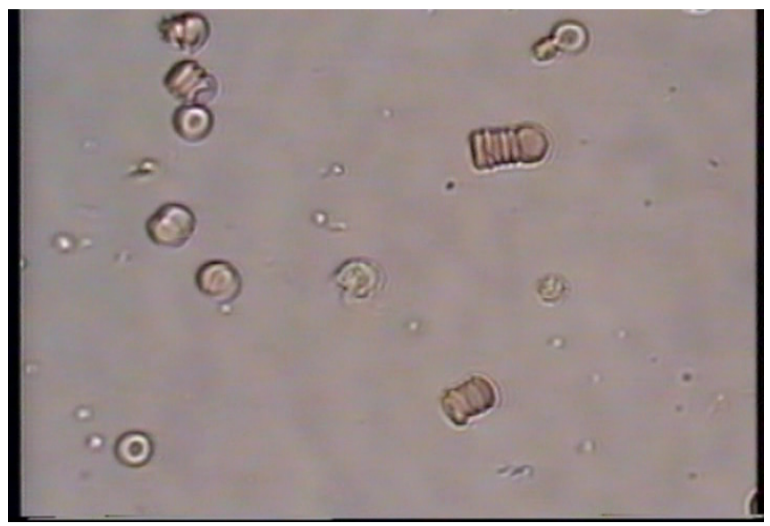

Leukocytes cell before exposure to RF radiation 


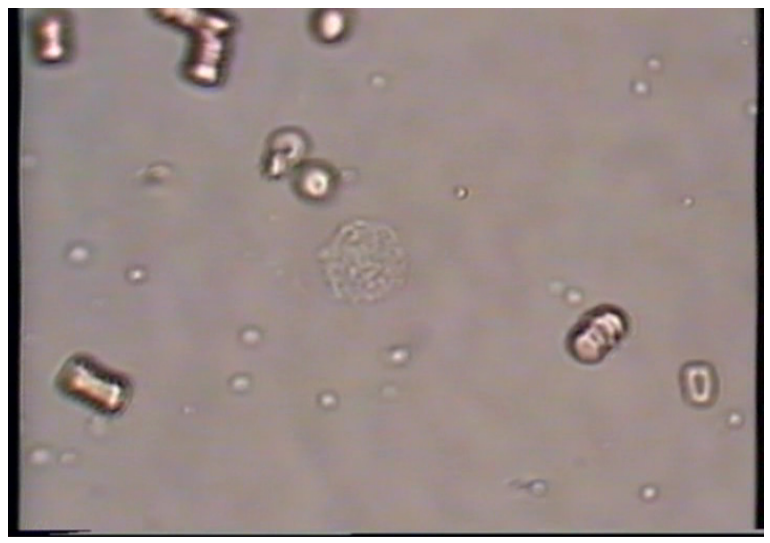

Damage to Leukocytes cell after exposure to RF radiation

Figure 4. RF radiation caused damage to the leukocytes cells from specific person's blood.

\section{Conclusions}

Our study was performed to investigate whether radio frequency (RF) field exposure could affect the activity of human immune system cells by studying the activity and behavior of human leukocytes (white blood cells) upon exposure to radiofrequency fields. Human blood Leukocytes were exposed to different temperatures and $1800 \mathrm{MHz}$ RF radiation. Our experimental results show significant change in leukocytes behavior upon the application of RF fields, including more rapid changes in shape, (cells shrinking, expanding, and rolling). The leukocytes tracking speed increased rapidly upon raising temperature between $29^{\circ} \mathrm{C}$ and $40^{\circ} \mathrm{C}$. One of the significant results we found, RF radiation caused damage to the leukocytes cells from specific person's blood the cells expanded and lost its ability to move.

\section{REFERENCES}

[1] L. Hardell, A. Hallquist, K. Mild, M. Carlberg, A. Pahlson \& A. Lilja,(2002)“Cellular and cordless telephones and the risk for brain tumours", Eur.J. Cancer Prev., vol. 11, no. 4, pp. 377-386.

[2] S. Lonn, A. Ahlbom, \& P. H. M. Feychting,(2004) "Mobile phone use and the risk of acoustic neuroma," Epidemiology, vol. 15, pp. 653-659.

[3] A. Aly, S. Deris \& N. Zaki, (2008)"Research review on the biological effect of cell phone radiation on human", 5th IEEE International Conference on Innovations in Information Technology, Al-Ain, UAE.

[4] G. Grimes \& F. Barnes, (1973)“A technique for studying chemotaxis of leukocytes in welldefined chemotactic fields", Experimental Cell Res., vol. 79, pp. 375-385.

[5] M. Dworkin \& K. H. Keller,(1977) "Solubility and diffusion coefficient of Adenosine $3: 5$ Monophosphate", J. Biol. Chem., vol. 252, no. 3, pp. 864-865.

[6] A. Cossarizza, S. Angioni, F. Petraglia, A. R. Genazzani, D. Monti, M. Capri, F. Bersani, R. Cadossi \&C. Franceschi,(1993) "Exposure to low frequency pulsed electromagnetic fields increases interleukin 1 and in-terleukin 6 production by human peripheral blood mononuclear cells", Experimental Cell Res., vol. 204, no. 2, pp. 385-387.

[7] I. Belyaev, Y. Alipov \& A. Matronchik,(1998) "Cell density dependent re-sponse of E. coli cells to weak elf magnetic fields," J. Bioelectromagn., vol. 19, pp. 300-309.

[8] F. Barnes \& Y. Kwon, (2005) "A theoretical study of the effects of RF field gradients in the vicinity of membranes", J. Bioelectromagn., vol. 26, no. 2, pp. 118-124. 
[9] O. Zeni, A. Schiavoni, A. Perrotta, D. Forigo, M. Deplano \& M.R. Scarfi,(2008) "Evaluation of genotoxic effects in human leukocytes after in vitro exposure to $1950 \mathrm{MHz}$ UMTS radiofrequency field", Bioelectromagnetics, 29:177-184.

[10] L. Hardell, \& A. Näsman, (1999)" Use of cellular telephones and the risk of brain tumors: a casecontrol study", Int. J. Oncol, 15:113-116.

[11] J.E. Muscat \& M.G. Malkin, (2000) "Handheld cellular telephone use and risk of brain cancer", JAMA 284:3001- 3007, 2000.

[12] Inskip P.D. \& Tarone RE, Hatch E.E., (2001) "Cellular telephone use and brain tumors" $N$ Engl J Med, 344:79-86.

[13] C. Johansen \& J.D. Boice , (2001) "Cellular telephones and cancer -- a nationwide cohort study in Denmark”, J Natl Cancer Inst 93:203-207.

[14] Rothman K..J. \& Chou C.K., Morgan R., (1996) "Assessment of cellular telephone and other radio frequency exposure for epidemiologic research", Epidemiology , 7:291-298.

[15] Ahlbom A., Day N., Feychting M., Roman E., Skinner J., Dockerty J., Linet M., McBride M., Michaelis J., Olsen J.H., Tynes T. \& Verkasalo P.K. (2000) “A pooled analysis of magnetic fields and childhood leukemia" Br J Cancer 83(5): 692-698.

[16] Deadman J.E., Armstrong B.G., McBride M.L., Gallagher M.A. \& Theriault G. (1999) "Exposures of children in Canada to 60-Hz magnetic and electric fields", Scand J Work Environ Health 25(4): 368-375.

[17] Foliart D.E., Iriye R.N., Silva J.M., Mezei G., Tarr K.J. \& Ebi K.L. (2002) "Correlation of yearto-year magnetic field exposure metrics among children in a leukemia survival study", J Expo Anal Environ Epidemiol 12: 441-447.

[18] Foliart D.E., Iriye R.N., Tarr K.J., Silva JM, Kavet R. \& Ebi K.L. (2001) Alternative magnetic field metrics: relationship to TWA, appliance use, and residential characteristic of children in a leukemia survival study. Bioelectromagnetics 22: 574-580. 